\title{
P379: Contribution of environmental measures in the implementation of a programme of infection control in Africa: an example of Senegal
}

\author{
$\mathrm{N} \mathrm{Mamadou}^{1 *}, \mathrm{~B}$ Ndoye $^{2}, \mathrm{M} \mathrm{SECK}^{1}$ \\ From 2nd International Conference on Prevention and Infection Control (ICPIC 2013) \\ Geneva, Switzerland. 25-28 June 2013
}

\section{Introduction}

In the context of strengthening the health system, the PRONALIN implemented in Senegal since 2004, has received funding from the Global Fund to operationalize its activities in all health facilities in the country. The objective is to assess the role of environmental measures in order to determine their contribution to the implementation of a program of infection control.

\section{Objectives}

To evaluate the performance of the environmental aspects have an impact on patient safety.

\section{Methods}

A concrete roadmap (with organizational measures and technical measures targeting certain basic processes priority) has been proposed care facilities. Grid supervision to enable an assessment activities was then used during formative supervisions biannual regularly conducted in all health facilities from January 2010 to December 2012.

\section{Results}

The organizational measures were performed in $96.13 \%$ of cases. Among the measures proposed techniques, waste management care comes first with a rate of $96 \%$ where the activity is partially completed, followed by hand hygiene (61\%), then with 55\% biocleaning. Other technical activities follow far behind.

\section{Conclusion}

In addition to hand hygiene has received wide campaign for many years, are the environmental measures that have given the best performance of technical measures.

In a context of shortage of human resources and material environmental measures remain the most technical measures to reach health facilities. This is of great interest because they allow a clear and noticeable improvement of working conditions, introduces personal teamwork, and all these positive results are a motivation for further work.

\section{Disclosure of interest}

None declared.

\section{Author details}

${ }^{1}$ PRONALIN, Ministry of Health, Dakar, Senegal. ${ }^{2}$ ICAN/RIPAQS, Dakar, Senegal.

Published: 20 June 2013

doi:10.1186/2047-2994-2-S1-P379

Cite this article as: Mamadou et al:: P379: Contribution of environmental measures in the implementation of a programme of infection control in Africa: an example of Senegal. Antimicrobial Resistance and Infection Control 2013 2(Suppl 1):P379.

${ }^{1}$ PRONALIN, Ministry of Health, Dakar, Senegal

Full list of author information is available at the end of the article

(c) 2013 Mamadou et al; licensee BioMed Central Ltd. This is an Open Access article distributed under the terms of the Creative 